\title{
Character Association and Path Analysis of Black Cumin (Nigella sativa L.) Genotypes under Different Irrigation Regimes
}

\author{
Kaosar BARDIDEH $^{1 *}$, Danial KAHRIZI ${ }^{2}$, Mohammad E. GHOBADI $^{2}$ \\ ${ }^{1}$ Islamic Azad University, Department of Plant Breeding, Farhikhtegan Bld., Shahid J'afari \\ Street, Kermanshah, Iran; Kosarbardi@yahoo.com ( ${ }^{*}$ corresponding author) \\ ${ }^{2}$ Razi University, Department of Agronomy and Plant Breeding, Imam Highway, Kermanshah, Iran
}

\begin{abstract}
Character association and path analysis were performed for black seed cultivars using a split-plots design based on RCBD with three replications. Three cultivars ('Varzaneh', 'Semirom' and 'Mobarakeh') were studied under three levels of irrigation (normal irrigation, irrigation with drought stress before and after flowering). Under normal and abnormal irrigations the relation of seed yield and three characters biological yield, number of capsule per plant and thousand seed weight were high, positive significantly $(p \leq 0.01)$; the relation between yield and number of sub branch was positive significantly $(p \leq 0.05)$. In terms of abnormal irrigation there was a positive significant correlation between essence percent and yield $(p \leq 0.05)$. Under normal irrigation the most direct effect of traits on yield was obtained from biological yield (0.778) followed the number of capsules per plant $(0.245)$. The most indirect effect of traits on yield was obtained from biological yield through thousand seed weight $(0.576)$ followed stem diameter through biological yield (0.468). Under water deficiency conditions the most direct effect of traits on yield was obtained from biological yield (0.811) followed the number of capsules per plant $(0.231)$. The most indirect effect of traits on yield was obtained from biological yield through thousand seed weight (0.562).
\end{abstract}

Keywords: black seed, drought stress after flowering, ketone and hydrocarbon monoterpens

\section{Introduction}

Nigella sativa L. (Ranunculaceae), usually known as black seed is one of the most pompous medicinal plant (Kacem and Meraihi, 2006). This specie is distributed in different parts of the world as well as Iran. It is extensively cultivated in some regions of the country (Nickavar et al., 2003). Black seed constituents have unique chemical properties (D'Antuono et al., 2002); it has more than one hundred different chemical components, including crude fiber, reducing sugars, mucilage, resins, flavonoids, alkaloids, organic acids, sterols, saponins, tannins, unsaturated fatty acids especially linoleic and oleic acid and many amino acids (Pourghassem-Gargari et al., 2009). Many medicinal properties were reported for black seed; for example, it decreased ischemia reperfusion injury (Yildiz et al., 2008). Anticancer activity of the plant extract was mentioned by Randhawa and Alghamdi (2011). Antimicrobial activity of black seed was reported (Chaieb et al., 2008).

The chemical compounds and medicinal properties of black seed affect by plant genotypes and agronomic treatments as well as other medicated plants (Gobbo-Beto and Lopes, 2007; Sahoo et al., 2010). Drought stress for many of plants is a serious problem but drought stress maybe change the amount of medicated compound of the plants (Khorasaninejad et al., 2011; Zheng et al., 2006).
Environmental conditions and genotype interaction affected the relationships among plant characters. Correlation and path analysis are the two best approach to determine these relations (Dalkani et al., 2011) that has been used by many researchers in different crops including many medicinal plants (Chitra and Rajamani, 2010; Karuppaiah and Senthil Kumar, 2010; Ibrahim et al., 2011). Relation among agronomic characters and the most medicinal components of black seed was studied shortly. Path analysis and correlation coefficient was used to evaluate these associations in Nigella sativa L. cultivars under water deficiency.

\section{Materials and methods}

Three replications randomized complete block splitplot design was applied to conduct the experiment during late spring and summer 2010. Latitude, longitude and altitude of experiment location were $47^{\circ} 9$ '08' E, 34 $42^{\prime} 27^{\prime \prime} \mathrm{N}$ and $1775 \mathrm{~m}$ respectively based on GPS reading. Three cultivars including 'Varzaneh', 'Semirom' and 'Mobarakeh' as sub plots were studied under three levels of irrigation embracing normal irrigation (to field capacity once a week), irrigation with drought stress before and after flowering (behind $40 \mathrm{~mm}$ evaporation from class A evaporation pan 10 day before flowering and 2 weeks after) as main plots. 
Seeds were sown on $19^{\text {th }}$ may with spacing of $50 \times 10 \mathrm{~cm}$ and depth of $3 \mathrm{~cm}$ and harvested on $15^{\text {th }}$ Sep. Day to capsule formation was recorded before harvesting. At physiological ripening data were recorded on five randomly selected plants for plant height, plant width, stem diameter, yield, biological yield, number of capsule per plant, number of seed per capsule, number of main branch, number of sub branch, thousand seed weight and harvest index. Percent of essence and some essence components including ketone and hydrocarbon monoterpens were determined based on the reported method by Nickavar et al. (2003). Simple linear correlation coefficients were computed and these coefficients were subjected to path analysis as described by Dewey and Lu (1959) using SPSS v.16 software.

\section{Results and discussion}

Correlation analysis for normal irrigation and water deficiency treatments are shown in Tab. 1 and 3 respectively. Under normal irrigation a negative significant correlation was found between number of day to capsule formation and four characters including number of main branch, essence percent, hydrocarbon monoterpenes and keton monoterpenes $(p \leq 0.05)$. Under abnormal irrigation there was a negative significant correlation between number of day to capsule formation and five characters including number of main branch, thousand seed weight, harvest index, hydrocarbon monoterpenes and keton monoterpenes $(p \leq 0.05)$; and high significant relation was found for number of day to capsule formation and essence percent $(p \leq 0.01)$. These results showed some changes for black seed characters relationships due to irrigation conditions. Also showed that under water deficiency some yield components like as thousand seed weight and harvest index were affected; and delay of capsule formation maybe decrease these components. As compare to normal irrigation, under water de- ficiency an increasing was found for relation of capsule formation time and essence percent. Therefor number of day to capsule formation is an important eco-morphological character for black seed production particularly under water deficiency conditions. Capsule formation was occurred after flowering and related to it. Golparvar et al. (2011) reported a negative significant correlation between essence amount and flowering time under variable conditions of plant growth in chamomile. Also Bannayan et al. (2008) showed non-decreasing changes in black seed essence after cutting irrigation.

Under normal irrigation and water deficiency conditions positive significant relation was found between plant width and two other characters comprising stem diameter and number of sub branch $(p \leq 0.05)$. However under abnormal irrigation the coefficients were increased that showed strength of stem and number of sub branch in black seed were more in wide plants. The eligible of these characters is the impact of them for seed yield increasing; because the number of sub branch in black seed is one of the most important yield components (Tonçer and Kizil, 2004).

In terms of irrigation the correlation coefficients of stem diameter and four characters yield, biological yield, number of capsule per plant and number of sub branch per plant were high, positive significantly $(p \leq 0.01)$. The relation between stem diameter and thousand seed weight was positive significantly $(p \leq 0.05)$. Under water deficiency conditions the relation between stem diameter and biological yield was positive significantly $(p \leq 0.05)$ but a high significant correlation was found for stem diameter and thousand seed weight $(p \leq 0.01)$; important traits like as yield and its components were discussed more than others. Here for the second time there were notable changes in character relationship due to change in water supply. These results illustrated that morphologic character af-

Tab. 1. Simple correlation coefficients of black seed characters under normal irrigation conditions

\begin{tabular}{|c|c|c|c|c|c|c|c|c|c|c|c|c|c|c|}
\hline Traits & DCF & $\mathrm{PH}$ & $\mathrm{PW}$ & SD & $\mathrm{YI}$ & $\mathrm{BIO}$ & $\mathrm{NC}$ & NS & $\mathrm{NMB}$ & NSB & $1000 S W$ & $\mathrm{HI}$ & $\% \mathrm{ES}$ & \%HYMONT \\
\hline $\mathrm{PH}$ & -0.061 & & & & & & & & & & & & & \\
\hline PW & -0.172 & 0.026 & & & & & & & & & & & & \\
\hline SD & -0.033 & 0.251 & $0.455^{\circ}$ & & & & & & & & & & & \\
\hline YI & -0.114 & 0.164 & 0.242 & $0.682^{*}$ & & & & & & & & & & \\
\hline $\mathrm{BIO}$ & -0.022 & 0.153 & 0.263 & $0.603^{*}$ & $0.971^{*}$ & & & & & & & & & \\
\hline $\mathrm{NC}$ & -0.141 & 0.185 & 0.371 & $0.731^{*}$ & $0.551^{*}$ & $0.519^{\prime \prime}$ & & & & & & & & \\
\hline NS & -0.085 & -0.173 & 0.329 & 0.054 & 0.094 & -0.034 & 0.117 & & & & & & & \\
\hline $\mathrm{NMB}$ & $-0.477^{\circ}$ & 0.341 & 0.266 & 0.339 & 0.133 & 0.085 & $0.662^{*}$ & 0.041 & & & & & & \\
\hline NSB & -0.161 & 0.205 & $0.402^{\circ}$ & $0.635^{\prime \prime}$ & $0.469^{\circ}$ & $0.465^{\circ}$ & $0.951^{*}$ & 0.142 & 0.674 & & & & & \\
\hline 1000SW & -0.008 & 0.223 & 0.157 & $0.451^{\circ}$ & $0.763^{*}$ & $0.748^{*}$ & 0.245 & -0.275 & 0.040 & 0.234 & & & & \\
\hline $\mathrm{HI}$ & -0.352 & -0.197 & -0.201 & 0.107 & 0.307 & $-0.504^{\circ}$ & 0.187 & 0.179 & 0.018 & -.245 & 0.281 & & & \\
\hline$\% \mathrm{ES}$ & $-0.431^{*}$ & -0.026 & 0.153 & 0.014 & 0.032 & -0.031 & 0.265 & -0.044 & 0.327 & 0.249 & 0.053 & 0.361 & & \\
\hline \% HY MONT & $-0.435^{\circ}$ & -0.027 & 0.142 & 0.017 & 0.031 & -0.047 & 0.266 & -.038 & 0.309 & 0.245 & 0.064 & 0.362 & $0.987^{*}$ & \\
\hline$\%$ KE MONT & $-0.462^{\circ}$ & -0.008 & 0.160 & 0.026 & 0.049 & -0.039 & 0.291 & -0.033 & 0.341 & 0.276 & 0.062 & 0.303 & $0.961^{*}$ & $0.946^{\circ}$ \\
\hline
\end{tabular}

** Significant correlation at $p \leq 0.01 .{ }^{*}$ Significant correlation at $p \leq 0.05$. DCF: Day to capsule formation, PH: Plant height, PW: Plant width, SD: Stem diameter, YI: Yield, BIO: Biological yield, NC: Number of capsule per plant, NS: Number of seed per capsule, NMB: Number of main branch, NSB: Number of sub branch, 1000SW: Thousand seed weight, HI: Harvest index, ES: essence percent, HY-MONT: Hydrocarbon monoterpene, KE-MONT: Ketone monoterpene 
106

Tab. 2. Direct and indirect effects of black seed characters on seed yield under normal irrigation conditions

\begin{tabular}{ccccccc}
\hline Variables & SD & BIO & NC & NSB & 1000 SW & Total \\
\hline SD & 0.135 & 0.081 & 0.103 & 0.085 & 0.061 & 0.682 \\
BIO & 0.468 & 0.778 & 0.395 & 0.358 & 0.576 & 0.971 \\
NC & 0.196 & 0.144 & 0.245 & 0.253 & 0.073 & 0.551 \\
NSB & -0.163 & -0.122 & -0.241 & -0.249 & -0.068 & 0.469 \\
\hline 1000 SW & 0.052 & 0.097 & 0.036 & 0.032 & 0.125 & 0.763 \\
Residual & 0.218 & & & & & \\
\hline
\end{tabular}

SD: Stem diameter, BIO: Biological yield, NC: Number of capsule per plant, NSB: Number of sub branch, 1000SW: Thousand seed weight (numbers on main diagonal are direct effects)

fected some yield components significantly differently depending on the available water. Therefore selection of black seed varieties for water deficiency conditions must be upon changes of yield component and other morphological character relations especially stem diameter and plant width. Stem diameter is one of the most important characters in many agronomic and horticultural medicinal plants for the best qualitative and quantitative yield ( $\mathrm{Fa}-$ kuta and Ojiekpon, 2004). In Ajowan, a medicinal plant from apiaceae, Dalkani et al. (2011) and in amaranths Layegh Haghighi et al. (2012) reported positive significant correlation between stem diameter and many other characters comprising yield components.

Under normal and abnormal irrigations the relation of seed yield and three characters biological yield, number of capsule per plant and thousand seed weight were high, positive significantly $(p \leq 0.01)$; the relation between yield and number of sub branch was positive significantly $(p \leq 0.05)$.

In terms of abnormal irrigation there was a positive significant correlation between essence percent and yield $(p \leq 0.05)$. Under normal irrigation and water deficiency conditions the relation of biological yield and two characters number of capsule per plant and thousand seed weight were high, positive significantly $(p \leq 0.01)$; the relation between biological yield and number of sub branch was positive significantly $(p \leq 0.05)$. Negative significant correlation was found for biological yield and harvest in$\operatorname{dex}(p \leq 0.05)$. Around the yield and yield components the correlation variability was sever. These results informed that under water deficiency essence amount and thousand seed weight of black seed had a key role on yield. The wa-

Tab. 3. Simple correlation coefficients of black seed characters under water deficiency conditions

\begin{tabular}{|c|c|c|c|c|c|c|c|c|c|c|c|c|c|c|}
\hline Traits & DCF & $\mathrm{PH}$ & $\mathrm{PW}$ & SD & $\mathrm{YI}$ & $\mathrm{BIO}$ & $\mathrm{NC}$ & NS & $\mathrm{NMB}$ & $\mathrm{NSB}$ & 1000SW & $\mathrm{HI}$ & $\% \mathrm{ES}$ & \%HYMONT \\
\hline PH & -0.032 & & & & & & & & & & & & & \\
\hline PW & -0.241 & 0.128 & & & & & & & & & & & & \\
\hline SD & -0.123 & 0.268 & $0.465^{\circ}$ & & & & & & & & & & & \\
\hline YI & -0.086 & 0.295 & 0.272 & $0.668^{*}$ & & & & & & & & & & \\
\hline $\mathrm{BIO}$ & -0.036 & 0.241 & 0.253 & $0.491^{\circ}$ & $0.928^{*}$ & & & & & & & & & \\
\hline $\mathrm{NC}$ & -0.217 & 0.215 & 0.348 & $0.693^{*}$ & $0.684^{*}$ & $0.622^{*}$ & & & & & & & & \\
\hline NS & -0.041 & -0.182 & 0.331 & 0.073 & 0.087 & -0.134 & 0.234 & & & & & & & \\
\hline $\mathrm{NMB}$ & $-0.501^{*}$ & 0.352 & 0.272 & 0.342 & 0.125 & 0.285 & $0.678^{* \prime}$ & 0.145 & & & & & & \\
\hline NSB & -0.241 & 0.235 & $0.462^{\circ}$ & $0.645^{*}$ & $0.482^{\circ}$ & $0.473^{\circ}$ & 0.972 & 0.172 & $0.688^{*}$ & & & & & \\
\hline 1000SW & $-0.478^{*}$ & 0.241 & 0.137 & $0.672^{*}$ & $0.815^{*}$ & $0.734^{*}$ & 0.318 & -0.295 & 0.243 & 0.2543 & & & & \\
\hline $\mathrm{HI}$ & $-0.452^{\circ}$ & -0.185 & -0.221 & 0.124 & 0.372 & $-0.511^{\circ}$ & 0.208 & 0.206 & 0.128 & -.238 & 0.277 & & & \\
\hline$\% \mathrm{ES}$ & $-0.533^{*}$ & -0.036 & 0.184 & 0.181 & $0.512^{\circ}$ & -0.061 & 0.293 & -0.078 & 0.302 & 0.256 & 0.062 & 0.372 & & \\
\hline$\%$ HY MONT & $-0.471^{\circ}$ & -0.037 & 0.132 & 0.123 & 0.181 & -0.042 & 0.301 & -.069 & 0.326 & 0.261 & 0.093 & 0.381 & $0.992^{*}$ & \\
\hline$\%$ KE MONT & -0.486 & -0.016 & 0.170 & 0.118 & 0.173 & -0.137 & 0.312 & -0.071 & 0.311 & 0.239 & 0.085 & 0.327 & $0.985^{*}$ & $0.968^{* *}$ \\
\hline
\end{tabular}

${ }^{* *}$ Significant correlation at $p \leq 0.01$. ${ }^{*}$ Significant correlation at $p \leq 0.05$. DCF: Day to capsule formation, PH: Plant height, PW: Plant width, SD: Stem diameter, YI: Yield, BIO: Biological yield, NC: Number of capsule per plant, NS: Number of seed per capsule, NMB: Number of main branch, NSB: Number of sub branch, 1000SW: Thousand seed weight, HI: Harvest index, ES: essence percent, HY-MONT: Hydrocarbon monoterpene, KE-MONT: Ketone monoterpene

Tab. 4. Direct and indirect effects of black seed characters on seed yield under water deficiency conditions

\begin{tabular}{ccccccccc}
\hline Variables & SD & BIO & NC & NSB & 1000 SW & \% ES & Total \\
\hline SD & 0.152 & 0.094 & 0.108 & 0.102 & 0.124 & 0.026 & 0.668 \\
BIO & 0.472 & 0.811 & 0.425 & 0.387 & 0.562 & 0.078 & 0.928 \\
NC & 0.203 & 0.182 & 0.272 & 0.231 & 0.112 & 0.033 & 0.684 \\
NSB & -0.181 & -0.162 & -0.183 & -0.242 & 0.067 & 0.022 & 0.482 \\
1000 SW & 0.058 & 0.105 & 0.078 & 0.115 & 0.231 & 0.065 & 0.815 \\
\% ES & 0.031 & 0.232 & 0.184 & 0.045 & 0.211 & 0.094 & 0.512 \\
Residual & 0.185 & & & & & & \\
\hline
\end{tabular}

SD: Stem diameter, BIO: Biological yield, NC: Number of capsule per plant, NSB: Number of sub branch, 1000SW: Thousand seed weight, ES: essence (numbers on main diagonal are direct effects) 
ter supply variation affected the relations among yield and yield components; therefore seed yield of black seed underground sever variability. Like this results reported by Bannayan et al. (2008), Iqbal et al. ( 2011), Ramadan et al. (2003).

Under all irrigation conditions the number of capsule per plant was correlated with two characters number of main and sub branch per plant positively significantly $(p \leq 0.01)$; but the relations under normal irrigation was more powerful. Number of sub and main branch per plant showed positive significant correlation $(p \leq 0.01)$. The number of branch per plant affected the number of capsule per plant and finally all affected seed yield per plant as previously reported by Dixit et al. (2012). Between essence percent and its components high positive significant correlation was found under normal and abnormal irrigation conditions $(p \leq 0.01)$. Also the amount of two kind of black seed monoterpenes was correlated positively significantly $(p \leq 0.01)$. In cumin Kahrizi et al. (2011) reported the positive significant correlation for essence percent and its components.

Path analysis for normal irrigation and abnormal water conditions were shown in Tab. 2 and 4 respectively. Under normal irrigation the most direct effect of traits on yield was obtained from biological yield (0.778) followed the number of capsules per plant (0.245). The most indirect effect of traits on yield was obtained from biological yield through thousand seed weight $(0.576)$ followed stem diameter through biological yield (0.468). Under water deficiency conditions the most direct effect of traits on yield was obtained from biological yield (0.811) followed the number of capsules per plant (0.272). The most indirect effect of traits on yield was obtained from biological yield through thousand seed weight $(0.562)$ followed stem diameter through biological yield (0.472) and biological yield through number of capsule per plant $(0.425)$. A notable subject for path analysis was direct and indirect effects of essence percent under abnormal irrigation wasn't evident before under normal irrigation conditions. Another difference between irrigation treatments was the value of direct and indirect effects. Under abnormal irrigation the direct effect of thousand seed weight and biological yield on yield were increased noteworthy but indirect effect of biological yield through thousand seed weight was decreased. Because of positive correlation between yield and essence percent, all direct and indirect effects of characters on yield influence the quality of black seed. Talle et al. (2012) showed effects of other traits on quality of the plant by path analysis in Melissa officinalis L. Kharizi et al. (2011) in cumin reported direct and indirect effects of yield components on essence percent.

\section{Conclusions}

The changes of characters relationship in black seed under different irrigation condition should be considered for variety selection and every plant breeding and agronomy program of the plant.

\section{References}

Chaieb K, Kouidhi B,Jrah H, Mahdouani K, Bakhrouf A (2008). Antibacterial activity Thymoquinone, an active principle of Nigella sativa and its potency to prevent bacterial biofilm formation. BMC Complem Altern Med 11(29):1-6.

Chitra R, Rajamani K (2010). Character association and path analysis in glory lily (Gloriosa superba L.). Intern J Fac Agric Biol 5(2):78-82.

Dalkani M, Darvishzadeh R, Hassani A (2011). Correlation and sequential path analysis in ajowan (Carum copticum L.). J Med Plants Res 5(2):211-216.

D’Antuono FL, Moretti A, Lovato FSA (2002). Seed yield, components, oil content and essential oil content and composition of Nigella sativa L. and Nigella damascene L. Indust Crops and Products 15:59-69.

Dewey DR, Lu KH (1959). A correlation and path analysis of components of crested wheat grass seed production. Agron J 51(6):515-518.

Dixit V, Prabha R Chaudhary BR (2012). Sodium azide induced polygenic variability in Nigella sativa L. Bot Res Internat 5(1):14-19.

Fakuta NM, Ojiekpon IF (2009). Correlation and paths analysis between stem diameter and other juvenile growths traits in twelve gum arabic (Acacia senegal (L) Willd) provenances. Report and Opinion 1(6):87-90.

Gobbo-Neto L, Lopes NP (2007). Medicinal plants: factors of influence on the content of secondary metabolites. Quimica Nova 30:374-381.

Golparvar AR, Ghasemi Pirbalouti A, Karimi M (2011). Determination of the effective traits on essence percent and dry flower yield in German chamomile (Matricaria chamomilla L.) populations. J Med Plants Res 5(14):3242-3246.

Ibrahim MM, Aboud KA, Hussein RM (2011). Genetic variability and path coefficient analysis in sweet basil for oil yield and its components under organic agriculture conditions. J Am Sci 7(6):150-157.

Iqbal MS, Inamullah AG, Abbasi FM, Qureshi SA, Ahmad H (2011). Study of nutritional characteristics, mineral nutrients and agro-biodiversity in black cumin (Nigella sativa L.) genotypes from Pakistan. Afr J Biotechnol 10(66):1475714766

Kacem R, Meraihi Z (2006). Effects of essential oil extracted from Nigella sativa (L.) seeds and its main components on human neutrophil elastase activity. Yakugaku Zasshi 126(4):301-305.

Kahrizi D, Azizi K, Haghi Y (2011). Relationships among yield and yield components and essence in cumin (Cuminum cyminum L.) under different climate conditions. Biharean Biol 5(1):63-68.

Karuppaiah P, Senthil Kumar P (2010). Correlation and path 
108 analysis in African marigold (Tagetes erecta L.). Electr J Plant Breed 1:217-220.

Khorasaninejad S, Mousavi A, Soltanloo H, Hemmati K, Khalighi A (2011). The effect of drought stress on growth parameters, essential oil yield and constituent peppermint (Mentha piperita L.). J Med Plants Res 5(22):5360-5365.

Layegh Haghighil M, Abbaszadeh B, Lebaschi MH, Vakili Shahrebabaki MA (2012). Evaluating effective traits on yield of two medicinal amaranths (Amaranthus hypochondriacus L. var. cim and var. kharkofski) in Karaj, Iran. Ann Biol Res 3(2):1014-1019.

Nickavar B, Mojab F, Javidnia K, Roodgar Amoli MA (2003). Chemical composition of the fixed and volatile oils of Nigella sativa L. from Iran. Zeitschrift fur Naturforsch J 58:629631.

Pourghassem-Gargari B, Ebrahimzadeh-Attary V, Rafraf M, Gorbani A (2009). Effect of dietary supplementation with Nigella sativa L. on serum lipid profile, lipid peroxidation and antioxidant defense system in hyperlipidemic rabbits. J Med Plants Res 3(10):815-821.

Ramadan MF, Kroh LW, Morsel JT (2003). Radical scavenging activity of black cumin (Nigella sativa L.), coriander (Coriandrum sativum L.), and niger (Guizotia abyssinica Cass.) crude seed oils and oil Fractions. Food Chem J 51(24):96619669.
Randhawa MA, Alghamdi MS (2011). Anticancer activity of Nigella sativa (black seed)-a review. Am J Chin Med 39(6):1075-1091.

Sahoo N, Manchikanti P, Dey S (2010). Herbal drugs: Standards and regulation. Fitoterapia 82:462-471.

Talle B, Darvish F, Mohammadi A, Abbaszadeh B, Rohami M (2012). Assessment of relationship between effective traits on yield and compounds of essential oil and morphological traits of lemon balm (Melissa officinalis L.) accessions using path analysis and canonical correlation. J Basic Appl Sci Res 2(4):3719-3723.

Tonçer O, Kizil S (2004). Effect of seed rate on agronomic and technologic characters of Nigella sativa L. Internat J Agric Biol 3:529-532.

Yildiz F, Coban S, Terzi A, Ates M, Aksoy N, Cakir H, Ocak AR, Bitiren M (2008). Nigella sativa relieves the deleterious effects of ischemia reperfusion injury on liver. World J Gastroenterol 14(33):5204-5209.

Zheng Y, Dixon M, Saxena PK (2006). Growing environment and nutrient availability affect the content of some phenolic compounds in Echinacea purpurea and Echinacea angustifolia. Planta Med 72 (15):1407-1414. 